\title{
LOS CORREDORES DE LONJA DE CÁDIZ Y JEREZ DE LA FRONTERA (SIGLOS XVI-XVIII)
}

\section{GUADALUPE CARRASCO GONZÁLEZ Universidad de Cádiz}

«...El intervenir (corredor) les era de mucha utilidad y augmento (a los mercaderes) por la expedición de sus mercadurías, porque les buscaban compradores y les concertaban, y el premio que por ello llevaban hera de muy poca considerazion...» (1)

El corredor es el intermediario comercial que relaciona a compradores y vendedores, cobrando a cambio de su asistencia un estipendio llamado corretaje. Los corredores eran, por tanto, intermediarios, interpretes y consejeros comerciales y jurídicos de los mercaderes. En este sentido los corredores fueron un instrumento favorecedor de las condiciones de los mercados y del comercio en general. Sin embargo, a pesar de este papel que juzgamos importantísimo, hasta la fecha las investigaciones sobre estos intermediarios mercantiles han sido bastante escasas en España, sólo algunos juristas y particularmente los propios corredores de comercio, han utilizado la figura del corredor comocentro de algunas de sus investigaciones.

Referencias al corredor aparecen en obras dedicadas a la historia de los Consulados de algunas plazas comerciales, como Barcelona, Málaga o Alicante (2). Sin embargo, estas pocas noticias, a veces tardías, sólo contemplan la existencia de distintos tipos de corredores, si gozaban o no de algunas ordenanzas y cual era su número. Sólo en el caso de las principales ciudades comerciales de la Corona de Aragón como Barcelona (3) y Valencia (4) hemos encontrado obras especificas sobre corredores.

Antonia Heredia Herrera recuperará con su artículo sobre los corredores de lonja de Sevilla y Cádiz el interés por esta figura comercial (5). Sin embargo, desde entonces se han impuesto las investigaciones de carácter más jurídico que histórico. Así José R. Cano dirigió un estudio colectivo sobre los corredores españoles basado fundamentalmente en fuentes legislativas (6). Alberto García Ulecía estudia algunos aspectos de las corredurías modernas, especialmente en las de Sevilla y Cádiz (7). Y más recientemente se han publicado las Memorias de la Antigua Universidad de Corredores de Aduana, Oreja y Lonja de la Ciudad de Sevilla, cuyo estudio introductorio nos ofrece una somera historia de los aspectos institucionales de la correduría sevillana (8).

Este' interés por parte de los historiadores del derecho proviene de las fuentes. En efecto, la documentación generada por los corredores, especialmente sus libros, ha llegado hasta nosotros en muy contadas ocasiones ( que se circunscriben prácticamente a la Corona de Aragón). Sin embargo, 
disponemos de la legislación general y la particular de cada ciudad reflejada en sus ordenanzas, o en el mejor de los casos en unos reglamentos específicos para los corredores.

No obstante en algunas plazas comerciales, los Consulados tenían competencia sobre las corredurías, por lo que entre sus fondos se pueden hallar documentos relativos al ejercicio de los corredores. Afortunadamente ése ha sido nuestro caso, pues entre los fondos de Consulados del Archivo General de Indias hemos hallado la mayor parte de la documentación producida por la Correduría mayor de Lonja de Cádiz entre 1750 y 1850. También han sido consultadas las Actas Capitulares de Cádiz y Jerez de la Frontera, así como los protocolos notariales, intentando buscar en este último caso pruebas claras de la labor y actividad de los corredores.

\section{La figura del corredor}

Los corredores eran elegidos por las autoridades municipales o consulares o por los propietarios de los oficios, en el caso de que éstos hubieran sido enajenados. Eran nombrados oficialmente para ejercer la función pública de mediación en las negociaciones mercantiles. Su actuación se realizaba en condiciones de monopolio, es decir, que detentaban la exclusividad del ejercicio de la mediación mercantil. Como consecuencia de ello, el corredor se convierte en un testigo privilegiado, de ahí que el siguiente paso en la evolución de su actividad sea el reconocimiento de la facultad de certificar acerca del negocio en que había mediado (9).

Para poder ejercer el oficio de corredor se exigían una serie de requisitos, entre los que se contaban ser español y vecino de la ciudad, demostrar experiencia comercial, y pagar una fianza. A cambio las autoridades competentes les otorgaban un título una vez se hubiese realizado el juramento de fidelidad.

Estas condiciones generales podían flexibilizarse según las circunstancias. Así el requisito de la nacionalidad no fue esencial para los corredores gaditanos. Aunque la legislación general prohibía a los extranjeros ser corredores, a los de Cádiz se les concedió el privilegio de nombrar entre ellos un número de extranjeros. De este modo aquí se dará una dualidad entre corredores naturales y extranjeros que se mantendrá hasta finales del siglo XVIII, a pesar de las constantes protestas de los nacionales.

Respecto a los conocimientos mercantiles, teóricamente era obligatorio que se probasen. Pero en una ciudad como Cádiz demostrar experiencia comercial no era difícil; se daba incluso la circunstancia de que durante el siglo XVII y la mayor parte del XVIII, los corredores procedían del mundo de los negocios. En muchos casos, la dedicación a la mediación era consecuencia de la mala fortuna en los negocios. En otras ocasiones, era un paso intermedio o definitivo para el mercader o comerciante con escasos recursos personales y 
monetarios. En cualquier caso, estos hombres de negocios, fracasados o no, encontraban en el oficio de corredor una vía lógica para ganarse la vida. Conocían suficientemente el mercado y el sector mercantil gaditanos, por tanto les resultaba bastante fácil realizar su labor como corredores con eficacia. Algunos eligieron el oficio público, convirtiéndose por tanto en corredores del número o corredores juramentados, otros ejercieron su actividad sin el respaldo de las autoridades, con el riesgo que ello conllevaba al ser considerados como corredores intrusos o «zánganos» (10). Sin embargo, ya desde mediados del siglo XVIII, cuando la profesión se gremializa o se convierte en corporación, el grupo mercantil dejará de ser el proveedor principal de corredores, a partir de entonces serán los propios hijos o nietos de los corredores los que pasen a engrosar sus filas.

La fianza era otra de las condiciones sin las que era imposible acceder al oficio de corredor. En Jerez de la Frontera, por ejemplo, se exigían estas fianzas desde el siglo XV (11). Sin embargo, en Cádiz, no será hasta la incorporación del oficio a la Corona en 1739 que la fianza se convierta en una condición imprescindible. En las primeras ordenanzas de la corporación se recoge expresamente la cuantía de esta que se fijaba en 500 ducados. Ya en el siglo XIX las dificultades económicas por las que atravesaron las corredurías de Cádiz, obligaron al gobierno a exigir, para cubrir las vacantes y las plazas nuevamente creadas, el pago de 1.000 pesos de fianza (12).

El oficio de corredor estaba regulado por unas ordenanzas. Estos reglamentos recogían diversos aspectos relacionados con el ejercicio de la profesión. Por ejemplo, en las ordenanzas gaditanas de 1750 (13), los primeros capítulos se dedican a los requisitos de entrada en el cuerpo y se fijaba el número de plazas. Más adelante se refieren al problema, siempre presente, del intrusismo. Así, recogen una primera declaración, en la que decían que ninguna persona que no fuera Corredor podía intervenir en negociaciones, bajo graves penas. El encargado de conocer este asunto era el Juez Conservador. También se regulaba en las ordenanzas la celebración de Juntas generales y especiales, se contemplaban igualmente los ingresos de la Universidad, que se lograban mediante repartimiento entre los corredores proporcionalmente a sus ingresos. En otro lugar, se exige a los Corredores la obligación de llevar libros que junto a «su declaración jurada, y apuntación formal puedan justificarse la perfección de los contratos a beneficio del Común Comercio, para en los casos donde los contrayentes estén discordes» (14). También se les prohíbe asegurar riesgos o comerciar por su cuenta. Al mismo tiempo se hace constar en las ordenanzas el arancel o corretaje que deben cobrar en función del negocio que se realiza.

\section{Origen y evolución de la corredurías de Cádiz.}

La Correduría Mayor de Cádiz fue creada por Felipe II en 1573. Y en ese año el rey hizo merced del cargo a D. Diego de Espinosa para todos los días de su vida. Se prorrogó la gracia en su hijo y nieto, y se perpetuó en cabeza de éste por juro de heredad (15). Así transcurrió durante más de un siglo, hasta que el 5 
de julio de 1739, Felipe V extinguió el privilegio e incorporó el oficio a la corona -movido por los quejas de los propios corredores. A cambio creó una universidad de corredores con la misma planta que la de Sevilla. Para compensar a la Casa del Marqués de la Vega de Boecillo, entonces propietario del oficio de Corredor Mayor, el monarca le concedió cuatro de las sesenta plazas creadas, dándole facultad para nombrar a las personas que debían desempeñarlas. El marqués reclamó los daños que le acontecían con la extinción del oficio, por lo que el Consejo de Hacienda determinó valorarlo en 44.000 pesos que se impondrían sobre la Correduría a favor de la Casa del Marqués de la Vega de Boecillo con los réditos del 3\%, lo que significaban 20.000 reales anuales. Esa cantidad debía satisfacerse del arrendamiento de las corredurías (16).

Después de la incorporación las 55 corredurías se sacaron a pública subasta para su arrendamiento. La primera postura la hicieron los propios corredores que ofrecieron 66.000 reales anuales para beneficiarla por tiempo de ocho años, a los que añadían 100.000 reales de vellón por «los caídos de los que han estado vacante», es decir, por el tiempo que había transcurrido sin arrendar. Si embargo, apareció un nuevo postor, D. Juan Joseph Durán, hombre de negocios francés y residente en la ciudad, que ofreció 82.500 reales anuales, por cada uno de los ocho años, y 140.000 reales por el tiempo que había estado vacante. Finalmente se remató en D. Bartolomé Nagle, vecino de Cádiz por precio de 128.906 reales y $8,5 \mathrm{mrs}$. de vellón al año. Así las cosas la corona decidió pregonar la venta del oficio adjudicándose a D. Agustín Ramírez de Ortuño en 3.000.000 reales de vellón (17). El 24 de noviembre de 1744 se le otorgaría Real Título de las 60 corredurías de lonja de la ciudad de Cádiz, con facultad para poder nombrar y expedir títulos de corredor y de nombrar un apoderado que las administrase bajo los ajustes en que conviniera con ellos. Las condiciones a las que se obligaba D. Agustín, eran las siguientes: no aumentar el número de corredores, ninguna persona podría usar del oficio de corredor sin el título correspondiente, ningún comerciante podría negociar sin la intervención de los corredores, y puesto que está mandado el establecimiento de la universidad de corredores, el propio $D$. Agustín redactaría unas ordenanzas para su gobierno, además se le permitía igualmente nombrar juez conservador para conocer todas las causas pertenecientes a los dichos oficios en primera instancia (18).

La realización de ordenanzas que se exigía en el contrato fue llevada a efecto. El primer proyecto de ordenanzas fue enviado en octubre de 1745 y examinadas por la Junta General de Comercio y Moneda. La Junta encontró algunas deficiencias, por lo que debieron formarse nuevas ordenanzas, que fueron finalmente aprobadas el 30 de octubre de 1750 (19).

Poco tiempo después afloraron dificultades en la administración del oficio lo cual obligó, en 1756, a D. Agustín a vender su parte, esto es, las tres quintas partes de las corredurías, con el cargo del tributo que se pagaba a la Casa del marqués de la Vega de Boecilllo. Un mes más tarde habiendo fallecido D. Antonio Ramírez de Ortuño, su hermano, los herederos vendieron las otras dos 
quintas partes de las corredurías. Los compradores en ambos caso fueron la universidad de cargadores que lo adquirió en las mismas cantidades que D. Agustín. El cuerpo de cargadores quiso comprar la universidad de corredores con sus propios fondos, sin embargo, por falta de estos fue necesario tomar dinero de prestamistas. Veintisiete comerciantes prestaron diferentes cantidades hasta completar el precio de 169.000 pesos en que se remató la venta. La universidad otorgaría las respectivas escrituras de obligación a favor de los prestamistas-accionistas, obligándose a pagarles un $4 \%$ anual a cada uno sobre su correspondiente desembolso, hasta que la universidad de cargadores restituyera las cantidades a los accionistas (20). Todavía en 1835 restaban por redimir 99:000 pesos (21).

Durante los años siguientes y hasta 1782, la actividad de la universidad de corredores transcurrió sin novedad, arrendando los accionistas los oficios por períodos de cinco años.

En 1782 D. Melchor de Monconil presentó un proyecto para la mejor administración de la Universidad de corredores lo que llevaba aparejado la incorporación de dicha Universidad a la Corona. A consulta del Consejo de Hacienda se eligió al dicho Melchor de Monconil para que en nombre de la Real Hacienda tomase posesión de la universidad de corredores, y lo hizo el 17 de noviembre de 1791. La universidad de corredores acudió al rey, pero el resultado del expediente voluminoso formado, se redujo a declarar que los corredores pagasen a los accionistas y al mayorazgo de Boecillo,los réditos y pensión que devengaban, mientras no fuese redimido por la Real Hacienda (22).

La universidad de corredores agobiada económicamente, llegó a encontrarse con atrasos superiores a los 30.000 pesos de réditos caídos. En tal situación acudió al gobierno por medio de su diputación, proponiendo varios arbitrios que no fueron tomados en consideración. En su lugar, en 1811, el gobierno recurrió al antiguo expediente de aumentar el número de plazas de corredores, para que con las contribuciones se cancelase la deuda (23).

Respecto al número de corredores, éste se incrementó progresivamente entre 1650 y 1750 , paralelamente a las necesidades del comercio. Para el siglo XVI no disponemos de datos porque en el título que Felipe II otorgó a D. Diego de Espinosa, sólo menciona el nombramiento de corredores, pero sin especificar un número concreto.

En el padrón de 1605, estudiado por Hipólito Sancho Sopranis (24), figuran nueve corredores. Este número se mantendrá a lo largo de la primera mitad del siglo, hasta que se hizo cargo de la correduría, como arrendador, D. Juan Francisco Patrón. En la escritura de arrendamiento, que firmó el año 1654 (25), considera que el aumento del tráfico en Cádiz justifica el incremento del número de plazas de corredores hasta un total de 17. En 1670 un nuevo contrato de arrendamiento otorga la administración de la Correduría Mayor a D. Gaspar 
de Morales y Quintanilla, corregidor de la Isla de León (26). En esta escritura constan los nombres de cincuenta y un corredores nombrados por don Gaspar. Ya a finales del siglo, en 1694 (27), el titular del oficio, obtiene, a cambio de un servicio de 9.000 pesos escudos, licencia para nombrar veinticuatro corredores extranjeros, con la condición de que el número de naturales no debía ser inferior a doce.

Durante los primeros años del siglo XVIII el número de plazas de corredor cubiertas según los distintos padrones fueron los siguientes: en 1709, 52 , en 1710,38 y en 1713,55 (28).

Con la incorporación del oficio a la Corona en 1739 se fija en sesenta el número de plazas de corredor, cincuenta y cinco que obtiene la Corona (quince son plazas de extranjeros y 40 de españoles), cuatro que se le conceden a la Casa del marqués de la Vega de Boecillo, como compensación por la incorporación, y una que se entrega a D. Antonio de Texada por los servicios prestados a la Corona (29).

En 1745 D. Agustín Ramírez de Ortuño adquiriría las sesenta plazas que componían la universidad de corredores, y un año después agregaría la plaza de la correduría del aceite que se había mantenido siempre aislada del resto. El número de plazas de la universidad ya no se modificaría hasta la nueva incorporación a la Corona de esta, que se verificaría en 1791. Entonces se propuso la creación de seis plazas supernumerarias, aunque parece que sólo se cubrieron tres. Y ya en 1811, como consecuencia de las dificultades financieras de la universidad de corredores el gobierno creó diecinueve plazas más, con lo que el número definitivo de corredores es de 80 corredores (30).

En el camino de este rápido recorrido sobre la evolución numérica de la Correduría de Cádiz, se nos quedan algunas propuestas que no llegaron a materializarse, pero que reflejan, en cierta forma, la realidad comercial de la ciudad.

Esencialmente la mayoría de las propuestas eran para incrementar el número de corredores, ofreciendo así una solución al problema de los intrusos. Una de estas peticiones fue la que hicieron varios corredores el año 1802. Estos juzgaban factible el aumento de las plazas hasta 150 ya que con ello se integrarían en la universidad a los corredores intrusos. El Consulado consideró, en su respuesta, que poner en práctica esta propuesta no acabaría con el problema de los intrusos, pues en listas mandadas confeccionar por el propio Consulado aparecen hasta 160 corredores que practican el oficio de la mediación clandestinamente (31).

Otra propuesta interesante, es la que hizo D. Manuel Cano Roxo, en 1804, para que se creara una correduría de seguros especializada, dado la gran cantidad de compañías de seguros existente en Cádiz (32). 
No menos importantes y frecuentes fueron las propuestas para eliminar las quince plazas de extranjeros, que se sucedieron a lo largo de todo el siglo XVII; las vías que se utilizaron para ello fueron unas veces peticiones para la extinción completa de estas plazas, alegando que los corredores españoles conocían sobradamente los idiomas y los usos de las plazas extranjeras. Otras veces,se utilizaron métodos más lentos pero eficaces, como fue ir cubriendo las vacantes extranjeras con españoles (33).

\section{Origen y evolución de las corredurías de Jerez de la Frontera.}

No podemos precisar con exactitud el origen de los corredores de Jerez. Sabemos que en las Cortes que se celebraron en esa ciudad, en 1268, se promulgó un ordenamiento de posturas y se estableció la prohibición de comerciar para los corredores. Los propios veinticuatros reconocen que la ciudad tenía «inmemorial posesión y costumbre» de nombrar corredores. En las antiguas ordenanzas municipales que datan de 1499 , aparece una relativa al oficio de corredor en la que se solicita a estos realicen su trabajo con independencia, sin favorecer al comprador o al vendedor (34). Pero no es hasta 1560 cuando se establecen unas ordenanzas de mayor extensión y detalle relativas únicamente a los corredores de lonja (35), obviando a los corredores de caballos y ganados.

En 1590 la corona embargaría para sí la posesión de los oficios, y el Corregidor, en nombre del Patrimonio Real arrendarían los oficios de corredores para los años de 1590 y 1591 en las personas que más ofrecieran por ellos, con facultad de que dicho arrendador (llamado Corredor Mayor) pudiese nombrar un número determinado de corredores para usar y ejercer dichos oficios (36). Sin embargo, la ciudad se quejó ante el Consejo de Hacienda mediante peticiones, por la «aspereza y rigor» de las condiciones con que el dicho oficio estaba arrendado y por los excesos que los corredores hacían en el uso y ejercicio de sus oficios. Para evitar estos inconvenientes, a partir de 1592 la renta de la Correduría Mayor no se arrendó, sino que se administró. Hasta que en enero de 1599, por Real Provisión, se hizo merced, por juro de heredad, a D. Enrique de Guzmán, Marques de Pobar, del oficio de Corredor Mayor de lonja de la ciudad de Jerez de la Frontera (37).

En Jerez, al igual que sucedía en otras ciudades españolas, había cierta especialización entre los corredores. Así, en función de ésta existían, a finales del siglo $\mathrm{XV}$, corredores de caballos o de bestias, corredores de ganado y corredores de lonja. A mediados del siglo XVI aparece un nuevo tipo de corredor especializado en las compraventas de paños, lanas, sargas y sedas (38). Entre esta fecha y los años finales del siglo XVIII se segrega de los corredores de lonja un grupo que se dedica única y exclusivamente a los negocios de granos (39). 
Las corredurías de caballos y ganado eran arrendadas por el cabildo anualmente. El título de corredor permitía el ejercicio del oficio solamente por un año. Cada corredor debía pagar una fianza, que en el año 1492, era de 10.000 mrs (40).

Los corredores de lonja eran nombrados por el cabildo jerezano anualmente, aunque había algunos corredores que poseían su plaza de forma vitalicia. Sin embargo, siempre que pudo el cabildo intentó transformar los títulos vitalicios en anuales (41). El número de corredores de lonja estaba limitado por una real ejecutoria a 32 corredores (42). A pesar de lo cual y de las protestas de los corredores, el cabildo, siempre que pudo, aumentó ese número alegando las necesidades del comercio.

El término corredor de lonja se aplica a todos los corredores que participasen en cualquier tipo de compraventas, exceptuando la de ganado y caballos. Se encargaban por tanto, de las negociaciones de vinos, pasas, mostos, arrope, granos, legumbres, esclavos, paños, heredades,... etc. En 1549 Pedro de Palma, sastre, sugirió al cabildo la necesidad de establecer corredores especializados en la negociación de paños, lanas, sargas y sedas, argumentando que en jerez se «hace tinte y aparejos para hacer paños y que en todas las ciudades y lugares donde se hacen tienen corredores hábiles para ello». Ante las protestas airadas de 16 corredores de lonja por el aumento del número de oficios, y porque las negociaciones de ese tipo de géneros siempre las habían realizado ellos, finalmente el cabildo decidió crear cuatro plazas de corredores de paños, lanas y sargas (43).

Las ordenanzas que se redactan en 1560 por los corredores de lonja y por el cabildo recogen no sólo una tabla de corretajes, sino También las negociaciones en que podían participar y cuales eran sus derechos y obligaciones. Al mismo tiempo se recoge en uno de los capítulos la creación de una lonja y su emplazamiento cerca de la plaza del Arenal (44). El establecimiento de un lugar donde llevar a cabo las negociaciones había sido un deseo repetidamente expresado por los corredores jerezanos al cabildo. En un principio se intentó dar solución adjudicándoles una tienda en la Alhóndiga, sin embargo en 1560 el cabildo adquiere «un solar de casas viejas» próximo a la plaza del Arenal para que sirva de Lonja. A cambio los corredores deberán hacerse cargo, desde enero de 1561 , de los 7.875 mrs. impuestos sobre la propiedad (45).

Así mismo, las ordenanzas determinan la organización administrativa de la Lonja. Se nombrarían anualmente dos Cónsules, y semestralmente un receptor y un fiel. Los corredores tendrían la obligación de acudir diariamente a la Lonja donde los cónsules distribuirían el trabajo.

Uno de los puntos más interesantes de estas ordenanzas es el que se refiere a la hospitalidad de los corredores. La hospitalidad para con los 
mercaderes ponía en peligro la imparcialidad del corredor, de ahí que, si bien no se prohíbe dar posada al mercader, por ser una costumbre antigua entre mercaderes, si se exige a los corredores declarar que mercader o mercaderes han sido sus huéspedes a fin de evitar tratos de favor.

Estas ordenanzas se aplicaron en Jerez hasta el año 1590 en que las corredurías de lonja pasaron a manos de la Corona y se arrendaron. En ese momento dejan de utilizarse las ordenanzas para aplicarse las condiciones del contrato de arrendamiento. Estas se reducían al cobro de un $1 \%$ de todo lo que se vendiese y contratase en la ciudad y su jurisdicción, en feria o fuera de feria. Para el cobro del porcentaje era necesario que todas las mercancías que entrasen, se registrasen; y para ello los dueños de las productos debían llamar a un corredor.

A consecuencia del arrendamiento los corredores cometieron excesos en el uso de sus oficios, llevando corretajes a los vecinos que vendían sin corredor, y exigiendo registrar mercancías que no habían sido negociadas, no dejando sacar ningún género de mercancías sin el albala de guía de los corređores, etc.

Pero, cuando el oficio fue adjudicado al marqués de Pobar, no cesaron las quejas, al contrario, continuaron las protestas por el cobro indiscriminado de corretajes. Finalmente la carta ejecutoria expedida por el consejo de Hacienda en 1625, determinó cuales eran funciones estrictas de los corredores nombrados por el marqués: Se pagaría corretaje (un 1\%) de todas las negociaciones bien en ferias o fuera de ellas, siempre que interviniese el corredor. Aquí debían incluirse los casos de compraventas por medio de factores y comisionistas que quedaban obligados a llamar a un corredor para su negociación (46).

El pleito entre la ciudad y los mercaderes de una parte y el marques de Pobar de otra, deja bien patente cual era el papel del corredor y cuales son los obstáculos y los fraudes que se podían presentar. Por un lado, queda clara la labor mediadora de corredor. Su trabajo consistía en buscar el mejor precio para un vendedor; sin embargo, era frecuente el fraude de corredores que favorecían a los mercaderes que vendían grandes partidas de.vino en detrimento de los pequeños productores.

El corretaje era considerado como el pago de un trabajo personal del corredor, pero el interés de los arrendadores y del marques por gravar todas las negociaciones, incluidas aquellas en las que no ha mediado corredor, implicaba convertir el corretaje en un nuevo tributo, que la ciudad y los mercaderes se niegan a pagar, al menos durante las ferias, por ser francas (47).

Otro de los problemas presentes en Jerez es el de los intrusos. Quizás donde más intrusos se localizan es en las ferias, donde acudían mercaderes flamencos e ingleses con sus tejidos a intercambiarlos por vino. La mayoría de estos comerciantes extranjeros tenían factores y apoderados entre los mercaderes jerezanos. Estos intermediarios conocían bien a los productores de 
vinos, de tal modo que su función era similar a la del corredor. Por eso los mercaderes se opusieron a la intervención de los corredores públicos en las ferias, sus funciones estaban cubiertas, pero además permitir a los corredores del número mediar en las negociaciones que se realizaban en las ferias, suponía introducir un elemento de control del fraude (48).

La correduría aparecía asî como un sistema de vigilancia más que de mediación, «como una suerte de inquisición comercial» (49). Esta función tardía de la correduría prueba que la institución no nace de manera artificial creada por los municipios para controlar el tráfico en su término. Antes al contrario esta función la adquiere cuando la correduría no es controlada por el cabildo sino que se considera como una renta más, y como tal es necesario sacarla el mayor partido.

\section{Concluyendo:}

Hemos presentado aquí dos Corredurías con orígenes diferentes pero con trayectorias posteriores similares. La Correduría de Jerez de la Frontera, de origen municipal, fue adquirida por el marqué de Pobar, y evolucionó hacia la gremialización. La Correduría Mayor de Cádiz, creada en 1573 ( no tenemos noticias de que existiera con anterioridad), tardó más de un siglo, pero terminó por convertirse en una corporación a mediados del siglo XVIII.

En ambos caso los oficios se adaptaron a las exigencias del comercio y sirvieron a las autoridades o a sus titulares, como instrumentos de control del tráfico. Sin embargo, esta función se verá obstaculizada por la aparición de gran cantidad de corredores intrusos.

El número de intrusos será consecuencia, por un lado de la corporativización del oficio de corredor, pues el gremio no responde a las necesidades crecientes del comercio; y por otro, el control del tráfico que asume el corredor del número en el ejercicio de su función será obviado por muchos comerciantes que preferirán la mediación de los corredores intrusos para evitar «dar pistas» a las autoridades sobre los negocios que desarrollan. 


\section{APENDICE}

\section{ORDENANZAS Y CAPITULOS REFERENTES A CORREDORES DE LONJA, aprobados el 15 de noviembre de 1560 (50).}

Que se les pague a los dichos corredores de corretaje y lleven e cobren los maravedis siguientes:

I. De cada bota de vino que contrataren los dichos corredores un real de plata, medyo el comprador, y medyo el vendedor.

III. De cada cahiz de trigo que se contratare e vendiere, un real de plata, medyo el comprador y medyo real el vendedor.

III. De cada cahiz de cebada, lleven e cobren diez maravedis del vendedor y otros diez maravedis del comprador.

IV. De cada cahiz de garvanços, o yeros o havas y otras semillas, un real, medyo el vendedor y el otro medyo el comprador.

V. De cada quintal de azeite veinte maravedis, diez el comprador y los otros diez el vendedor.

VI. De cualquier esclavo varón o hembra, un ducado de cada parte, del comprador e vendedor, de cada uno medyo ducado.

VII. De cada carretada de uva medio real, un quartillo el vendedor e otro quartillo el comprador.

VIII. De cada caxco de bota vacio que compraren o vendieren, ocho maravedis, quatro maravedis del comprador e quatro del vendedor.

IX. De las heredades rayces y de los tributos y de otras qualesquier mercadurias tocantes al oficio de corredor de lonja que se contrataren e vendieren, de que fuerencorredores; se le pague medyo por ciento de qualquier parte, conviene a saber, medyo por ciento de la cantidad que se contratare del vendedor e otro medio por ciento el comprador.

$\mathrm{X}$. Item, que los dichos corredores por la dicha lonja tengan casa conosçida y señalada donde esten y residan los dichos corredores de lonja y acudan los mercaderes y contratantes, y que los dichos corredores tengan lybro de sus cuentas e repartimientos, y un arca con tres llaves, donde se recojan y esten los dineros que ovieren e cobraren de corretajes, los dichos corredore, para que se reparta por todos igualmente, y que uno de los dichos corredores tenga cargo de escribir lo tocante a la dicha lonja, y así mismo un fiel de los mismos corredores. XI. Item, que para la conservación e guarda de la lonja, ninguno de los corredores de lonja haga contratación alguna que no se de cuenta y se escriva en la lonja, ny lleven corretajes fuera de la dicha lonja por sy ny por interpositas personas, directa ny indirecta, so pena que pierda la parte que le pertenesçiere de los derechos del arca que hasta ally ovieren sydo, e que el tal corredor sea espelido y extraño de la lonja por tiempo de un mes como sy no fuese corredor, y que sy dentro del dicho mes de suspensión usare dicho ofiçio de corredor dentro en la lonja e fuera, que por el mismo caso haya perdido e pierda el ofiçio de corredor que tuviere y quede vaco para que esta ciudad provea de el conforme a la executoria real de su magestad que sobre corredores tiene.

XII. Item, que la ciudad mande pregonar con penas de camara que ningun vecino ni otra persona se entremeta en el dicho ofiçio de corredor a lo usar en ninguna, 
aunque sea por via de encomienda, ni factoria, sino que todo lo que se contratare, comprare e vendiere sea en la lonja e por mano de los corredores de lonja, porque se haga razon y se sepa verdad sin perjuicio de la ciudad y sus vecinos. E que la ciudad mande de guardar e cumplir estos capitulos por ordenança de la ciudad con las demas penas convenientes. Los quales capitulos estan firmados de los corredores: Pedro de Loja, Vicente Garcia, Alonso de Quemada, Luis de Cabzedo, Juan Forno, Juan Moreno, Diego Gonzalez, Alonso Garcia, Alonso Arias Portillo, Juan Lopez Vela, Alonso de la Peña, Francisco Martin, Andrés Perez, Bartolomé Garcia, Benyto Sanchez Peraça, Francisco Garcia Pocasangre, Martin de Mena, Guillermo Nicolas, Juan Pedro, Martin Ruiz.

\section{CAPITULOS SOBRE LA CORREDURIA DE LONJA AÑADIDOS Y APROBADOS POR EL CABILDO DE JEREZ (19 de noviembre de 1560).}

I. Lo primero quel señorio e dicho que tiene para nombrar corredores en lugar de los que vacaren por muerte o por demeritos conviene a la exma. ciudad.

II. Item, que la dicha ciudad pueda nombrar en cada un año un veinticuatro e un jurado que tengan cuenta con lo que convenga a la lonja y de hecho si se cumple la horden que se pone juntamente con la justicia.

III. Item, que la justicia y diputados cada mes nombren de los mismos corredores dos dellos por consules para que asistan en la lonja y hagan el repartimiento, y los demás corredores esten e pasen por lo que ordenaren y mandaren los dichos dos consules en todo lo tocante a la dicha lonja, y que asi mismo la justicia e diputados nombren un recebtor y un fiel de los mismos corredores de seys e seys meses que es por Navidad.

IV. Item, que los mercaderes de qualquier naçion que viniere a comprar a esta ciudad pueden posar donde quysieren, aunque sea en casa de los corredores, con tanto que el corredor cuya casa posare no pueda andar con ellos para comprar vinos o otras cosas que obiere de comprar, ni los hijos o herederos dellos si tambien fueren corredores.

V. Item, que los corredores donde posaren los mercaderes susodichos luego el mismo dia los manifieste en la lonja sy vinieren a posar de dia y sy vinieren de noche que luego otro dia por la mañana los manifieste en la lonja.

VI. Item, que los dichos consules y el recebtor y el fiel que fueren nombrados asy esten siempre en la dicha lonja desde las siete de la mañana hasta el toque de la oración del Avemarya.

VII. Item, que los dichos corredores todos asistan en la lonja para que los dichos consules les manden lo que han de hacer y no teniendo justo impedimento de los dichos consules que pague dos reales cada dia en que no hubiere a la lonja $\backslash .$. roto...। a pobres vergonzantes o para la cera del santisimo $\backslash . .$. roto...। de los consules y sy alguno se ubiere enfermo o retraydo $\backslash$....roto...।.

VIII. Item, que los corredores no lleven ni pidan de corretaje \...roto...\ otra $\backslash$...roto...\ de lo que esta declarado por los capitulos que $\backslash .$. roto...\ dados por los dichos corredores aunque ora de voluntad de los mercaderes o vendedores, y que los dichos corredores sean obligados (a) tapar e clavar las botas y a encaminarles sus haciendas si les llevan más derechos, y que los consules den e largo a los 
otros corredores, los que ellos se nombraren para tapar y encamynar las botas e tras cosas.

IX. Item, que los corredores que son ofueren de lonja perpetuamente, de los dineros de la cada (caxa?) que se ganaren han de ser obligados en cada un año por Pasqua de Navidad a casar una huerfana pobre que sea de los mismos corredores hija o pariente, y elegida por ellos persona que los dichos corredores de su voluntad $\backslash$...roto... $\backslash$ por buena obra y que la den doce mil maravedis cada año.

$\mathrm{X}$. Item, que el corredor de lonja que excedire o fuere contra los dichos capitulos que pierda el oficio y que la ciudad lo pueda dar y proveer a quien quisiere, e demas de esto caiga e incurra en pena de seis mill maravedis, el tercio para la camara de su magestad y para esta ciudad por iguales partes, y el tercio parte para el que lo demandadre y el tercio parte para el juez que lo denunciare, lo que se entiende en los capitulos que tengan estas penas particulares.

XI. Item, que se les señala a los dichos corredores por sytio un solar de las casas viejas, el que esta a la mano derecha como sale del Arenal, con tanto se paguen los sietemill ochocientos y setenta y cinco maravedis en que son rematados cada año por los tributos y que comiençe a correr desde primero de enero de mill y quinientos sesenta y uno.

XII. Item, que ninguna persona que no sea corredor nombrado y con facultad de la ciudad no se entrometa a usar el dicho oficio por ninguna manera, directa $o$ yndirectamente, so pena de seis mill maravedis aplicados por la horden dicha y demas de las penas que nasçieren por leyes e por derechos de dichos reynos . XIII. Item, que la ciudad resçiba en si de poder quitar y añadir los capitulos e ordenanzas que le pareciere que convengan a la buene horden y conservacion de la dicha lonja, e cedo en lo que toca a los dichos y al perjuicio de los oficios que en esto nuestro aya mandato de los oficios de la lonja que entre ellas han de elegir.

XIII. Item, en cuanto al onzeno y doceno capitulos se dice que no se pueda façer corretaje fuera de la lonja ni llevar derechos fuera della, se entiende respecto de los mercaderes forasteros y su respecto de los vecinos que quisieren vender sus haciendas, trigo, cevada o azeite, esclavos o heredades por que el corredor por ninguna mano pagare lo suso dicho sea obligado a lo manifestar en la lonja el propio derecho so la dicha pena de perder el oficio y de seismill maravedis aplicados en la forma susodicha, porque de otra manera los vecinos recibyrian perjuicio y dejaryan de hacer sus haziendas y venderlas por no yrla proximo a manifestar, con que lo hagan los vecinos personalmente o por sus criados y no por otra interposita persona.

XIV. Item, que los dichos corredores dentro de dos años son obligados a fazer de fabricar e labrar el solar que de suso esta señalado para la lonja, de primero e segundo suelos con sus corredores delante a la plaza del Arenal, al hilo de los de la sevillana y en el dicho tiempo de dos años gsten en la dicha cas trescientos veinte ducados y paguen el dicho tributo cada año.

$X V$. Item, que despues los dichos corredores han de gastar en la dicha casa y edificio la dicha cantidad de trescientos y veinte ducados, los que agora son, que en los corredores que vacaren en los seis años proximos despues de pagar / ...roto.../ lonja el arrendador que se nombrare y exerciere en su lugar de e pague 
a los herederos del corredor que vacare todo lo que le cupiere al tal corredor y sy /...roto.../plazos los seis años hasta diez años que pague el corredor que sea en su lugar del que vacare a sus herederos la mitad y pagados los seis años no se les pague ninguna cosa el que se eligiere pasados dos años.

\section{NOTAS.}

(1) Archivo Municipal de Jerez, Histórico, C. 1, nº 20.

(2) Sobre Barcelona hay referencias dispersas sobre los corredores llamados «de oreja» en diversas obras de Historia económica y social de la ciudad. Por ejemplo, en la de CARRERA PUJAL, La Barcelona del segle XVIII, págs. 368371. Sobre los corredores de Málaga se puede ver F. BEJARANO, Historia del Consulado y de la Junta de Comercio de Málaga. 1785-1859, Madrid, 1948. Y sobre Alicante la obra de F. FIGUERAS PACHECO, El Consulado marítimo y terrestre de Alicante y pueblos del obispado de Orihuela, Alicante, 1957, también contiene referencias a los corredores.

(3) Noticias históricas del Colegio de Corredores Reales del antiguo comercio catalán, Barcelona, 1904.

(4) ESCRIVA, El gremio de corredores de oreja, Tesis Doctoral, Valencia, 1941.

(5) HEREDIA HERRERA, A., «Los corredores de lonja en Sevilla y Cádiz», Archivo Hispalense, $2^{\text {a }}$ época (1970), págs. 183-197.

(6) CANO, J.R. (dir.), El Corredor de Comercio Colegiado. Historia de una profesión, Valencia, 1985.

(7) GARCIA ULECIA, A., «El papel de corredores y escribanos en el cobro de alcabalas», Historia, Instituciones, Documentos, $\mathrm{n}^{\circ} 13$ (1986), págs. 89-110. También del mismo autor, «Las ordenanzas de los corredores de lonja de Sevilla», Historia. Instituciones. Documentos, n 14, (1987), págs. 161-179; y «Naturaleza y extranjería en las corredurías de lonja del Antiguo Régimen», Anuario de Historia del Derecho Español, tomo LXI (1991), págs. 87-109.

(8) RIOS SEGARRA, E. (ed.), Memorias de la Antigua Universidad de corredores de aduana, oreja y lonja de la ciudad de Sevilla, Teruel, 1993.

(9) DOMINGO GONZALEZ, V., La correduría pública en el derecho mercantil español: estatuto, función y ámbito de competencia de los corredores de comercio colegiados, Madrid, 1986, págs. 17-41.

(10) D. Joseph de la Vega nos aclara la diferencia entre corredores del número y los «zánganos»: «En cuanto a los corredores, hay unos que son puestos por el magistrado a que llaman jurados, por el juramento que hacen de no negociar 
nada por su cuenta, y se estrechan a cierto número limitado, sin poderse dilatar, sino en ocasión de muerte, o de algún favor bien señalado, que suele suceder muy raras veces; $y$ hay otros a que llaman çanganos (que son unos insectos parecidos a las abejas que en lugar de labrar la miel la comen) por entender los primeros que les usurpan la miel, y supuesto que si los llamasen a juicio pagarían la pena que se impone al que les cercena la ganancia...destos últimos luze tan infinita multitud que es el más único remedio de los infelices y el más precioso refugio de los aflictos...», VEGA, J. de la., Diálogos curiosos entre un philosopho agudo, un mercader discreto y un accionista erudito..., Amsterdam, 1688.

(11) A.M.J., Histórico, C.1, n 40.

(12) A.G.I., Consulados, leg. 1755.

(13) B.N. Manuscritos, 2/10847.

(14) Ibídem.

(15) Felipe III por despacho de 22 de mayo de 1706 hizo merced a D. Diego de Espinosa (hijo), en las mismas condiciones que lo tenía su padre, de la Correduría mayor de lonja. Y por real cédula de 30 de junio de 1616 le amplió dicha merced por dos vidas sucesivas más, después de la suya.

Felipe IV por despacho de 20 de diciembre de 1632 lo confirmó, y le dio título; y en consideración a los servicios prestados por D. Diego y sus antecesores, por real cédula de 30 de noviembre de 1643 perpetuó el oficio por juro de heredad. A.G.I., Consulados leg. 1753.

(16) Archivo Municipal de Cádiz, Actas Capitulares, t. 10102, f. 23.

(17) Sobre D. Agustín Ramírez Ortuño véase MARTINEZ SHAW, C., «Un mercader gaditano del siglo XVIII: Agustín Ramírez Ortuño», Archivo Hispalense, $\mathrm{n}^{\circ} 196$, (1981), págs. 29-41.

(18) Ibídem.

(19) B.N., Manuscritos $2 / 10847$.

(20) A.G.I., Consulados leg. 1754.

(21) A.G.I., Consulados leg. 1756.

(22) A.G.I., Consulados leg. 1754.

(23) A.G.I., Consulados leg. 1756. 
(24) SANCHO SOPRANIS, H., «Perfil demográfico de Cádiz en el siglo XVI», Estudios de Historia Social de España, tomo II (1952), págs. 533-612.

(25) A.H.P.C., Protocolos notariales, Cádiz, tomo 1298, f. 25.

(26) A.H.P.C., protocolos notariales, Cádiz, tomo 976, f. 80-84.

(27) A.M.C., Actas Capitulares, tomo 10084, f. 406-26.

(28) A.M.C., Padrones, n 1002, 1003, 1004.

(29) A.M.C., Actas Capitulares tomo 10100, f. 38-47.

(30) A.G.I., Consulados leg. 1756.

(31) A.G.I., Consulados leg. 1754, no 22 y 24.

(32) Ibídem.

(33) A.G.I., Consulados leg. 1753, $\mathrm{n}^{\circ} 27$.

(34) A.M.J., Histórico, C.1, $\mathrm{n}^{\circ}$ 40; Antiguas Ordenanzas Municipales, Hordenanza de corredores (1499).

(35) A.M.J., Actas Capitulares, año 1560, f. 548.

(36) A.M.J., Histórico, C.1, nº 20.

(37) Ibídem.

(38) A.M.J., Actas Capitulares, año 1549, f. 311 y 324.

(39) A.M.J., Histórico, leg. 182, exp. 5523.

(40) A.M.J., Histórico, C.1, nº 40.

(41) A.M.J., Actas Capitulares, año 1552, f. 89v-90.

(42) A.M.J., Actas Capitulares, año 1685, f. 90.

(43) A.M.J., Actas Capitulares, año 1549, f. 324 y 351.

(44) Véase la transcripción de estas ordenanzas en el apéndice.

(45) Ibídem.

(46) A.M.J., Histórico, C. 1, nº 20. 
(47) Ibídem.

(48) Los corredores del número se quejan de que en las ferias los vecinos de la ciudad compran vino y arrope par alos extranjeros, con lo que defraudan los derehcos de salida que inicialmente se fijaban en un $2,5 \%$, pero que en 1620 se situaron en 1 real. Del mismo modo los tejidos que los mercaderes extranjeros introducían en la ciudad pagando un $2,5 \%$ de derechos de entrada, si intervenía corredor en la negociación debería pagarse además el $1 \%$ que se fijaba en las condiciones del real título. De ahí el interés de los comerciantes por impedir la entrada de los corredores en las ferias. Pero finalmente la carta ejecutoria de 1625 obligó a factores y comisionistas a usar de corredor en sus negociaciones. En definitiva esta medida iba dirigida contra el fraude que se practicaba en las ferias por los vecinos de la ciudad que compraban «vinos y arropes» para mercaderes extranjeros.

(49) VAN HOUTE, J., «Les courtiers au Moyen Age. Origen et caracteristiques d' une institution commerciale en Europe Occidentale», Revue historique de Droit français et etranger, tomo XVI, (1936), pág. 129.

(50) A.M.J., Actas Capitulares, año 1560, f. 961 y ss. 